PM standards should be reconsidered" (5). Although there would be costs to expanding the monitoring network and implementing additional air quality standards, these costs need to be weighed against the benefits to public health and quality of life and, as clearly shown here, costs that taxpayers are already shouldering through programs such as Medicaid.

Author disclosures are available with the text of this article at www.atsjournals.org.

Matthew J. Strickland, Ph.D., M.P.H.

School of Community Health Sciences

University of Nevada

Reno, Nevada

ORCID ID: 0000-0003-3027-5470 (M.J.S.)

\section{References}

1. Cohen AJ, Brauer M, Burnett R, Anderson HR, Frostad J, Estep K, et al. Estimates and 25-year trends of the global burden of disease attributable to ambient air pollution: an analysis of data from the Global Burden of Diseases Study 2015. Lancet 2017;389: 1907-1918.

2. Adar SD, Filigrana PA, Clements N, Peel JL. Ambient coarse particulate matter and human health: a systematic review and meta-analysis. Curr Environ Health Rep 2014;1:258-274.

3. Bellavia A, Urch B, Speck M, Brook RD, Scott JA, Albetti B, et al. DNA hypomethylation, ambient particulate matter, and increased blood pressure: findings from controlled human exposure experiments. J Am Heart Assoc 2013;2:e000212.

4. Byrd JB, Morishita M, Bard RL, Das R, Wang L, Sun Z, et al. Acute increase in blood pressure during inhalation of coarse particulate matter air pollution from an urban location. J Am Soc Hypertens 2016; 10:133-139.e4.
5. Keet CA, Keller JP, Peng RD. Long-term coarse particulate matter exposure is associated with asthma among children in Medicaid. Am J Respir Crit Care Med 2018;197:737-746.

6. U.S. Environmental Protection Agency (EPA). Integrated science assessment (ISA) for particulate matter (Final Report, Dec 2009). EPA/600/R-608/139F. Washington, DC: EPA; 2009.

7. U.S. Census Bureau. Federal statistical research data centers [accessed 2017 Dec 1]. Available from: https://www.census.gov/about/adrm/ fsrdc/locations.html.

8. O'Lenick CR, Winquist A, Mulholland JA, Friberg MD, Chang HH, Kramer $\mathrm{MR}$, et al. Assessment of neighbourhood-level socioeconomic status as a modifier of air pollution-asthma associations among children in Atlanta. J Epidemiol Community Health 2017;71:129-136.

9. Georgetown University Health Policy Institute, Center for Children and Families. Medicaid's role for children [accessed 2017 Dec 1]. Available from: https://ccf.georgetown.edu/wp-content/uploads/2016/06/Medicaidand-Children-update-Jan-2017-rev.pdf.

10. Cheung K, Shafer MM, Schauer JJ, Sioutas C. Historical trends in the mass and chemical species concentrations of coarse particulate matter in the Los Angeles Basin and relation to sources and air quality regulations. J Air Waste Manag Assoc 2012;62:541-556.

11. Sturtz TM, Adar SD, Gould T, Larson TV. Constrained source apportionment of coarse particulate matter and selected trace elements in three cities from the Multi-Ethnic Study of Atherosclerosis. Atmos Environ (1994) 2014;84:65-77.

12. Vanderpool R, Ellestad TG, Harmon MK, Hanley T, Scheffe R, Hunike E, et al. Multi-site evaluations of candidate methodologies for determining coarse particulate matter (PMC) concentrations. Presented at Managing Environmental Quality Systems. April 15, 2004, Tampa, FL.

13. Jahan K, Mehta $Y$. Potential for natural brine for anti-icing and de-icing. 2012 [accessed 2017 Dec 1]. Available from: https://ntl.bts.gov/lib/ 46000/46300/46341/finalbrinereport.pdf.

14. Office of Highway Policy Information, Federal Highway Administration. FHWA forecasts of vehicle miles traveled (VMT). 2017 May 4 [accessed 2017 Dec 1]. Available from: https://www.fhwa.dot. gov/policyinformation/tables/vmt/vmt_forecast_sum.pdf.

Copyright @ 2018 by the American Thoracic Society

\title{
Sepsis-associated Encephalopathy Is Septic
}

Sepsis-associated brain dysfunction is considered to be unrelated to bacterial infection. That is why we commonly use the word "encephalopathy" rather than "encephalitis." This assertion is challenged by Singer and colleagues (pp. 747-756) in the current issue of the Journal (1). The authors found that experimental peritonitis results in gut-originating polymicrobial dissemination to the brain during the acute phase, with bacteria remaining viable even 5 days after the surgical procedure. They also found that the cerebral presence of bacteria was associated with neuroinflammation, as evidenced by the increased expression of S100A8 in the brain parenchyma and iba-1 (ionized calcium-binding adaptor molecule 1) by microglial cells. Interestingly, the cerebral presence of bacteria was also documented in patients who had died from sepsis. Previous postmortem neuropathology studies have reported cerebral abscesses in approximately $10 \%$ of patients with septic shock (2). However, the originality of the present study rests upon the

Originally Published in Press as DOI: 10.1164/rccm.201712-2593ED on January 23, 2018 identification of gut microbiota by direct gene sequencing of the brain during sepsis. These results raise several methodological, pathophysiological, and therapeutic issues.

First, the presence, in physiologic conditions, of bacteria in the central nervous system has been reported. A recent study reported the presence of $\alpha$-proteobacteria in brain samples obtained during neurosurgery (3). These findings have raised several questions in the scientific community. Because the brain is considered as an immune privileged organ, and isolated germs are considered as laboratory and operating-room contaminants, the concept of cerebral microbiota has not been widely accepted (4).

Second, the current results indicate that pathogens have crossed the blood-brain barrier (BBB). There are potentially three mechanisms: 1 ) the transcellular and paracellular pathways (for example, those used by leukocytes), 2) the neural route (5), and 3) the "Trojan horse" trick (6). The neural route has been implicated in Listeria rhombencephalitis, as Listeria monocytogenes can reach the brain via the cranial nerves (7). By analogy, the vagal nerve might be the gut-brain route for bacterial dissemination in the case of peritonitis. The Trojan horse pathway consists of 
monocytes carrying microbes that are released into the brain parenchyma after cell migration (6). To illustrate the complexity of the mechanisms involved in crossing of the BBB by pathogens, the binding of the meningococcus to endothelial CD147 leads to the formation of bacterial colonies that can resist the blood flow, facilitating the paracellular crossing by impairing the BBB tight junctions (8). It is conceivable that in sepsis-associated encephalopathy the bacteria remain outside the brain, on the abluminal side of the endothelial cells. The absence of reactional gliosis, which is commonly observed in brain infection, might support this hypothesis. Electron microscopy might be useful for determining exactly the localization of the pathogens.

Third, irrespective of their localization, it would be interesting to assess the extent to which bacterial dissemination contributes to the ischemic and neuroinflammatory processes that serve as central mechanisms in the pathogenesis of sepsisassociated encephalopathy. The ischemic process results in both macrocirculatory and microcirculatory dysfunction, with the latter being related to endothelial activation and clotting disorder (2). Schematically, the neuroinflammatory process involves endothelial activation, BBB dysfunction, passage of inflammatory mediators, and microglial activation that amplifies this process by releasing more inflammatory mediators. Certainly, an assessment of BBB dysfunction as either a consequence or a cause of bacterial dissemination would be highly interesting, as it might identify potential therapeutic targets. The microglial cells, along with their role in immune surveillance of the brain, are involved in neuronal plasticity. The activation of microglial cells is a highly complex phenomenon (9). Microglial cells are highly reactive to various stimuli of diverse types (e.g., microbial or immune) and origins (humoral or neural). Therefore, the presence of bacteria can certainly activate microglial cells, along with many other stimuli. When activated, microglial cells can in time acquire different morphological (ranging from hyperamified to amoeboid) and immune (proinflammatory to antiinflammatory) phenotypes that have increased neuroprotective or neurotoxic activity. At the end of this process, microglial cells may be primed, meaning that they will be particularly reactive to a second stimulus (10). However, there is no univocal relationship among morphology, immune status, functional properties, and pathogenic effects. This indicates how challenging it is to modulate microglial cells.

From a therapeutic point of view, before antiinflammatory interventions are attempted, antibiotic strategies should certainly be tested first. One might argue that the occurrence of encephalopathy in patients with sepsis should prompt the administration of prolonged antibiotic therapy, as in the treatment of meningitis or brain abscesses. Given our current state of knowledge, this certainly cannot be recommended. However, brain infection should be more systematically sought via brain imaging and cerebrospinal fluid analysis in the case of altered mental status in patients with sepsis.

In conclusion, the present study raises challenging issues about the mechanisms and consequences of bacterial dissemination into the brain during sepsis, emphasizes the necessity to rule out brain infection, and perhaps calls for reconsidering the duration of antibiotherapy in a patient with sepsis who is developing brain dysfunction. Finally, the article raises a semantic issue: should the term "sepsis-associated encephalopathy" be replaced by "sepsisassociated encephalitis"?

Author disclosures are available with the text of this article at www.atsjournals.org.

Aurélien Mazeraud, Ph.D.

Department of Infection and Epidemiology

Institut Pasteur

Paris, France

Medical and Surgical Neurointensive Care

Centre Hospitalier Sainte Anne

Paris, France

and

Université Paris Descartes

Paris, France

Fernando A. Bozza

Fundacao Oswaldo Cruz

Rio de Janeiro, Brazil

Tarek Sharshar, M.D., Ph.D.

Department of Infection and Epidemiology

Institut Pasteur

Paris, France

Medical and Surgical Neurointensive Care

Centre Hospitalier Sainte Anne

Paris, France

and

Université Paris Descartes

Paris, France

ORCID IDs: 0000-0001-8473-7779 (A.M.); 0000-0003-4878-0256 (F.A.B.); 0000-0003-2276-0951 (T.S.).

\section{References}

1. Singer BH, Dickson RP, Denstaedt SJ, Newstead MW, Kim K, Falkowski NR, et al. Bacterial dissemination to the brain in sepsis. Am J Respir Crit Care Med 2017;197:747-756.

2. Sharshar T, Annane D, de la Grandmaison GL, Brouland JP, Hopkinson NS, Françoise G. The neuropathology of septic shock. Brain Pathol 2004;14:21-33.

3. Branton WG, Ellestad KK, Maingat F, Wheatley BM, Rud E, Warren RL, et al. Brain microbial populations in HIV/AIDS: $\alpha$-proteobacteria predominate independent of host immune status. PLoS One 2013;8: e54673.

4. Salter SJ, Cox MJ, Turek EM, Calus ST, Cookson WO, Moffatt MF, et al. Reagent and laboratory contamination can critically impact sequence-based microbiome analyses. BMC Biol 2014;12:87.

5. Dramsi S, Lévi S, Triller A, Cossart P. Entry of Listeria monocytogenes into neurons occurs by cell-to-cell spread: an in vitro study. Infect Immun 1998;66:4461-4468.

6. Kim KS. Mechanisms of microbial traversal of the blood-brain barrier. Nat Rev Microbiol 2008;6:625-634.

7. Disson O, Lecuit M. Targeting of the central nervous system by Listeria monocytogenes. Virulence 2012;3:213-221.

8. Bernard SC, Simpson N, Join-Lambert O, Federici C, Laran-Chich M-P, Maïssa N, et al. Pathogenic Neisseria meningitidis utilizes CD147 for vascular colonization. Nat Med 2014;20:725-731.

9. Ransohoff RM, Perry VH. Microglial physiology: unique stimuli, specialized responses. Annu Rev Immunol 2009;27:119-145.

10. Cunningham $\mathrm{C}$. Microglia and neurodegeneration: the role of systemic inflammation. Glia 2013;61:71-90.

Copyright () 2018 by the American Thoracic Society 